\title{
Changes in relative fitness and frailty across the adult lifespan: evidence from the Canadian National Population Health Survey
}

\author{
Kenneth Rockwood MD, Xiaowei Song PhD, Arnold Mitnitski PhD
}

See related commentary by Crome and Lally at www.cmaj.ca/cgi/doi/10.1503/cmaj.110626.

\begin{abstract}
- Abstract
Background: The prevalence of frailty increases with age in older adults, but frailty is largely unreported for younger adults, where its associated risk is less clear. Furthermore, less is known about how frailty changes over time among younger adults. We estimated the prevalence and outcomes of frailty, in relation to accumulation of deficits, across the adult lifespan.
\end{abstract}

Methods: We analyzed data for communitydwelling respondents (age 15-102 years at baseline) to the longitudinal component of the National Population Health Survey, with seven two-year cycles, beginning 1994-1995. The outcomes were death, use of health services and change in health status, measured in terms of a Frailty Index constructed from 42 self-reported health variables.

Results: The sample consisted of 14713 respondents (54.2\% women). Vital status was known for more than $99 \%$ of the respondents. The prevalence of frailty increased with age, from $2.0 \%$
(95\% confidence interval $[\mathrm{Cl}] 1.7 \%-2.4 \%$ ) among those younger than 30 years to $22.4 \%$ (95\% Cl 19.0\%-25.8\%) for those older than age 65 , including $43.7 \%(95 \% \mathrm{Cl} 37.1 \%-50.8 \%)$ for those 85 and older. At all ages, the 160-month mortality rate was lower among relatively fit people than among those who were frail (e.g., $2 \%$ v. $16 \%$ at age $40 ; 42 \%$ v. $83 \%$ at age 75 or older). These relatively fit people tended to remain relatively fit over time. Relative to all other groups, a greater proportion of the most frail people used health services at baseline $(28.3 \%, 95 \% \mathrm{Cl} 21.5 \%-35.5 \%)$ and at each follow-up cycle $(26.7 \%, 95 \% \mathrm{Cl} 15.4 \%-28.0 \%)$.

Interpretation: Deficits accumulated with age across the adult spectrum. At all ages, a higher Frailty Index was associated with higher mortality and greater use of health care services. At younger ages, recovery to the relatively fittest state was common, but the chance of complete recovery declined with age.
$\mathrm{O}$ $\mathrm{n}$ average, health declines with age. Even so, at any given age the health status across a group of people varies. Variability in health status and in the risk for adverse outcomes for people of the same age is referred to as "frailty," which typically has been studied among older adults. ${ }^{1,2}$ Although frailty can be operationalized in different ways, in general, people who report having no health problems are more likely to be fit than people who report having many problems. Unsurprisingly, the chance of adverse outcomes - death, admission to a long-term care institution or to hospital, or worsening of health status - increases with the number of problems that the individual has. ${ }^{3,4}$

The antecedents of frailty appear to arise some time before old age, ${ }^{5-9}$ although how frailty emerges as people age, whether it carries the same risk at all ages and the extent to which it fluctuates are less clear. ${ }^{910}$ In the study reported here, we evaluated changes in relative fitness and frailty across the adult lifespan. Our objectives were to investigate the effect of age on the prevalence of relative fitness and frailty, the characteristics of people who were relatively fit in comparison with those who were frail across the adult lifespan, the effects of fitness and frailty on mortality in relation to age and sex, and the characteristics of people who maintained the highest levels of fitness across a decade relative to those who at any point reported any decline.

\section{Methods}

\section{Participants}

In the longitudinal component of the National Population Health Survey, conducted by Statistics Canada, 17276 people were followed every two years from 1994-1995 to 2006-2007 (Appendix 1, available at www.cmaj.ca/cgi/content/full/cmaj $.101271 / \mathrm{DC} 1)$. The survey asked about physical and mental health status, use of health services,
Competing interests: Kenneth Rockwood is seeking funding to develop a commercial version of the Frailty Index. He is president of and owns stock options in DementiaGuide Inc., a company that tracks outcomes in clinical trials of dementia. The company has received contracts from Pfizer Canada, Medivation, GlaxoSmithKline and Janssen Alzheimer Immunotherapy. Dr. Rockwood will receive royalties from a publisher for work on a textbook about geriatric medicine. No competing interests declared by Xiaowei Song or Arnold Mitnitski.

This article has been peer reviewed.

Correspondence to: Dr. Kenneth Rockwood, kenneth.rockwood@dal.ca

CMAJ 2011. DOI:10.1503 /cmaj.101271 
physical activities and social environment. The survey employed multistage stratification by geographic and socioeconomic characteristics and clustering by Census Enumeration Area. ${ }^{11,12} \mathrm{We}$ obtained access to the data through an agreement with the Atlantic Research Data Centre of Statistics Canada. Statistics Canada officials reviewed the analyses to verify confidentiality and appropriate weighting.

\section{Frailty Index}

We defined frailty in relation to the accumulation of deficits in a so-called Frailty Index, which grades the person's risk. We scored each individual's Frailty Index by counting the number of deficits and dividing this count by the total number of deficits considered (42 in this study; see Appendix 2, available at www.cmaj.ca/cgi /content/full/cmaj.101271/DC1). We did not limit deficits to those typically used in studying older adults (and thus deficits such as asthma and food allergy were included), and we took into consideration symptoms (e.g., impaired hearing), disabilities (e.g., help needed to prepare meals) and diseases (e.g., high blood pressure, migraine, glaucoma). For example, a person who reported poor self-rated health, arthritis and trouble climbing stairs would have three deficits and an index score of $3 / 42$ or 0.07 . Defining relative fitness and frailty in this way has been validated in several samples, ${ }^{2,5,13-19}$ including the National Population Health Survey. ${ }^{9.20}$ The Frailty Index typically shows a consistent increase with age (about 3\% per year on a log scale), a high correlation with the risk of death (typically $r^{2}>0.95$ for the correlation between mortality and mean Frailty Index scores) and a submaximal limit (i.e., $<1 \%$ of people have a Frailty Index above 0.67). ${ }^{21}$ Although the "frailty phenotype" definition is more widely used, ${ }^{22}$ it requires performance measures not used in this survey. People with a Frailty Index score of 0 to 0.03 are almost never judged as being frail on a clinical basis, ${ }^{23}$ nor are they defined as phenotypically frail. ${ }^{3}$ Similarly, those with a Frailty Index score above 0.21 have less than a $5 \%$ chance of being defined as phenotypically "robust." 22

\section{Definitions and prevalence estimates}

Although the Frailty Index is determined on a continuous scale, the scale can be subdivided for comparisons of different health states., ${ }^{3,22}$ In this study, assignment as relatively fit (Frailty Index $\leq 0.03$, i.e., no or only one deficit), less fit ( 0.03 $<$ Frailty Index $\leq 0.10)$, least fit $(0.10<$ Frailty Index $\leq 0.21$ ), frail (Frailty Index $>0.21$ ) and, where disaggregating is permitted, most frail (Frailty Index $\geq 0.45$ ) followed established cut points. ${ }^{22}$ To help understand the antecedents of frailty, we compared people who were relatively fit at baseline with those who were frail at baseline and followed them to determine change in health status.

We calculated prevalence estimates for baseline fitness and constructed $95 \%$ confidence intervals [CIs]. We weighted the data by applying the longitudinal response master variables from the National Population Health Survey. Where complete data were not available for each cycle for individual respondents, we censored the data when the respondents were last seen in the study. For those who returned in later cycles, we applied the "last case carry forward" method, which assumed there was no change from the prior cycle. ${ }^{24} \mathrm{We}$ applied multiple imputation to substitute missing values for any variable that had less than 5\% missing data; otherwise, variables with missing data were excluded from consideration as potential health deficits.

\section{Outcome measures}

We described outcomes on the basis of all data points for seven cycles (14 years). For participants who died, the date of death was recorded from the death certificate. We estimated time to admission to a long-term care institution by imputing the median time between cycles in which incident admission to an institution had occurred. In accordance with the confidentiality requirements of Statistics Canada, data points with a sample size less than six are not reported.

\section{Statistical analysis}

We estimated age-specific prevalence and outcomes for various levels of relative fitness or frailty and aggregated these data by five-year intervals from age 15 years. We evaluated the distribution of participants' health states and mortality at each cycle. We compared proportions using $\chi^{2}$ tests, and we analyzed the relation between Frailty Index and age using regression techniques. We evaluated survival using Kaplan-Meier curves, with bivariable comparisons based on the Mantel-Cox log-rank test and multivariable analyses based on the Cox proportional hazards model adjusted by age, sex and education level. We set the statistical significance level at $p=0.05$.

\section{Ethics approval}

The National Population Health Survey was approved by the Statistics Canada ethics review process, and participants provided oral informed consent. The Research Ethics Committee of the Capital District Health Authority, Halifax, Nova Scotia, approved the additional analyses reported here. 


\section{Results}

Of 17276 participants, 14713 (54.2\% women) were at least 15 years of age (mean 44.3, standard deviation [SD] 18.3, range 15-102 years) at baseline, but 457 of these did not complete all questions in the baseline survey (Appendix 1, available at www.cmaj.ca/cgi/content/full/cmaj $.101271 / \mathrm{DC} 1)$. Vital status after 12 years was known for more than $99 \%$ of respondents, including $2020(13.7 \%)$ who died. Health status at all six follow-up cycles could not be obtained for a total of 3338 people (22.7\%). Compared with those with complete data for all seven interviews, people with incomplete data were more likely to have been younger (median 38 v. 42 years), male (female/male ratio $1.1: 1$ v. 1.3:1), less educated (48\% v. $61 \%$ completed secondary school or higher) and slightly frailer (mean Frailty Index 0.067 [SD 0.070] v. 0.064 [SD 0.068]; median 0.03 for both groups) (Appendix 3, available at www.cmaj.ca/cgi/content/full/cmaj.101271/DC1).
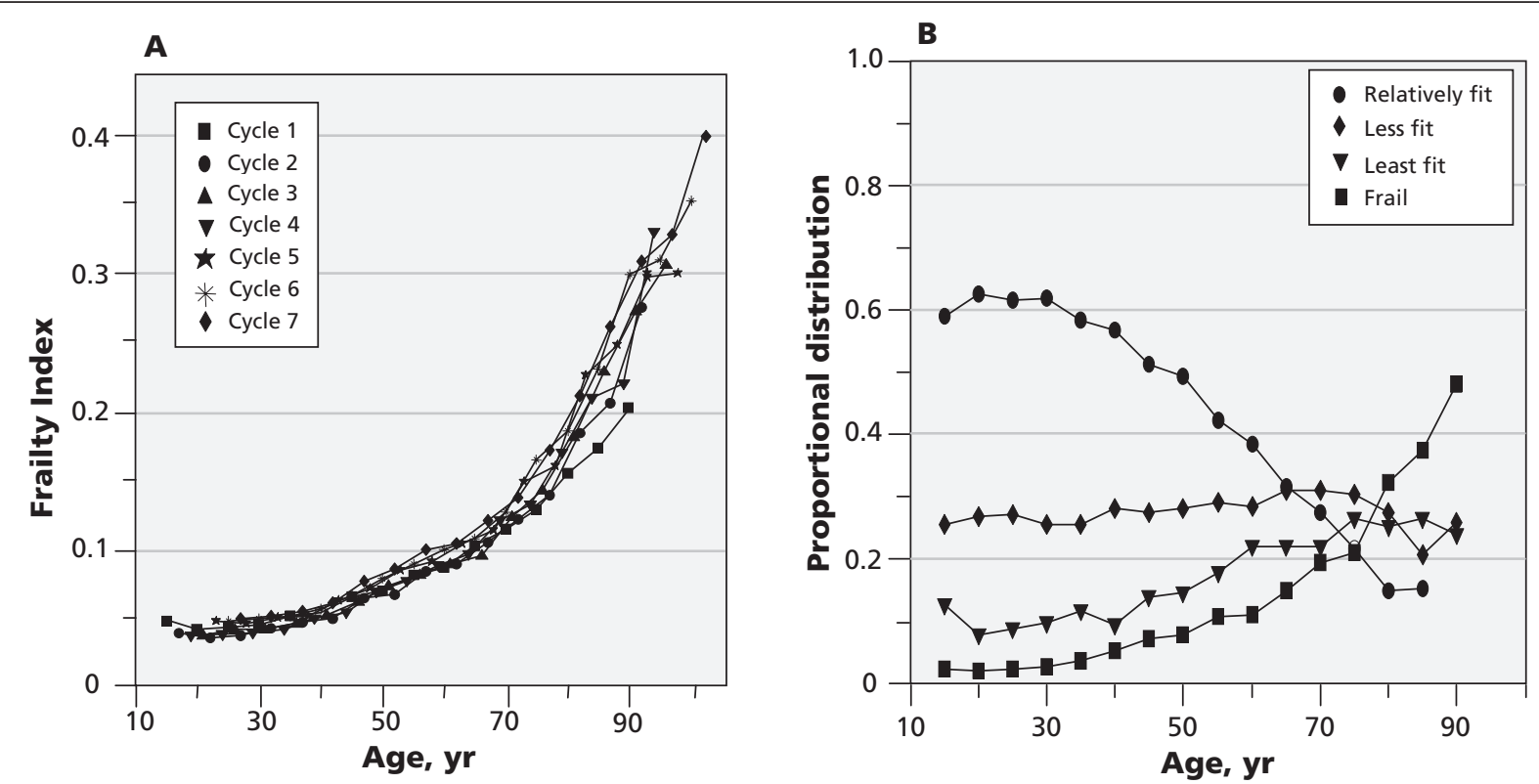

Figure 1: (A) Mean values of Frailty Index at each study cycle as a function of age ( $n=14$ 127, population-weighted). (B) Proportion of participants with each health status at baseline, as a function of age $(n=14127$, population-weighted). Definitions of fitness categories: relatively fit, Frailty Index $\leq 0.03$; less fit, $0.03<$ Frailty Index $\leq 0.10$; least fit, $0.10<$ Frailty Index $\leq 0.21$; and frail, Frailty Index $>0.21$.

Table 1: Baseline characteristics of the study sample, by health status*

\begin{tabular}{|c|c|c|c|c|c|}
\hline Characteristic & Overall & Relatively fit & Less fit & Least fit & Frail \\
\hline Sample sizet & 14127 & 7183 & 3887 & 2038 & 1019 \\
\hline \multicolumn{6}{|l|}{ Age, yr } \\
\hline Mean (SD) & $44(18)$ & $38(16)$ & $46(18)$ & $54(19)$ & $64(17)$ \\
\hline Median & 42 & 35 & 43 & 55 & 67 \\
\hline Sex ratio, female/male & 1.11 & 1.10 & 1.12 & 1.13 & 1.18 \\
\hline $\begin{array}{l}\text { Education, \% with secondary } \\
\text { school graduation }\end{array}$ & 52 & 64 & 57 & 48 & 36 \\
\hline $\begin{array}{l}\text { Marital status, \% married } \\
(95 \% \mathrm{Cl})\end{array}$ & $57.0(56.0-58.0)$ & $63.0(62.0-64.0)$ & $62.0(60.0-64.0)$ & $56.0(54.0-58.0)$ & $44.0(41.0-47.0)$ \\
\hline Hospital stay, $\neq \%(95 \% \mathrm{Cl})$ & $6.9(6.5-7.3)$ & $5.0(4.2-5.3)$ & $6.0(5.1-6.8)$ & $9.6(8.2-10.9)$ & $18.4(16.4-20.5)$ \\
\hline Frailty Index, $§$ mean (SD) & $0.068(0.080)$ & $0.010(0.011)$ & $0.066(0.019)$ & $0.148(0.027)$ & $0.310(0.080)$ \\
\hline
\end{tabular}

Note: $\mathrm{Cl}=$ confidence interval, $\mathrm{SD}=$ standard deviation.

*In keeping with the privacy policy of Statistics Canada, data are not shown for the $1 \%$ of participants categorized as "most frail," as some points would have had values less than six. Reported data are population-weighted.

tRespondents 15 years of age or older.

¥Within the two weeks preceding the survey.

§Frailty Index = number of self-reported deficits $\div 42$ (the total number of deficits assessed). 
There was no acceleration of nonresponse to the survey in relation to age or frailty.

At all seven interviews, the distribution of the Frailty Index was skewed, with a long right tail (Figure 1A). More specifically, less than $1 \%$ of people were categorized as most frail (Frailty Index $\geq 0.45$ ). Most respondents had a low degree of frailty (median 0.03). About half of the respondents $(7183 ; 50.8 \%, 95 \%$ CI $50.5 \%-$ $51.1 \%$ ) reported high relative fitness at baseline, whereas $1019(7.2 \%, 95 \%$ CI 6.9\%-7.5\%) were frail. At each cycle, the mean value of the Frailty Index increased exponentially with age (Figure 1A), from $2.0 \%$ (95\% CI 1.7\%-2.4\%) among those younger than 30 years to $22.4 \%$ (95\% CI $19.0 \%-25.8 \%)$ for those older than age 65 , including $43.7 \%$ (95\% CI $37.1 \%-50.8 \%$ ) for those 85 and older. The mean slope of the line of the logarithm of the Frailty Index versus age was
0.029 (95\% CI 0.027-0.031), and the intercept was -3.90 ( $95 \% \mathrm{CI}-4.07$ to -3.80$)$. The proportion of people with the highest relative fitness at baseline declined monotonically with age, and the proportion who were frail increased exponentially (Figure 1B). The prevalence lines for the relatively fittest and frail groups crossed at about age 75 .

The relatively fittest people at baseline were generally much younger, more often married and more highly educated than those who were frail (Table 1). Men, in general, accumulated fewer deficits than did women (Table 1). Health status changed over the 12 years. Those who were relatively fittest at baseline tended to remain healthy (Figure 2A), whereas those who started in frail health were the most likely to die (Figure 2B). The chance of staying at the highest level of fitness across all seven cycles declined with age,
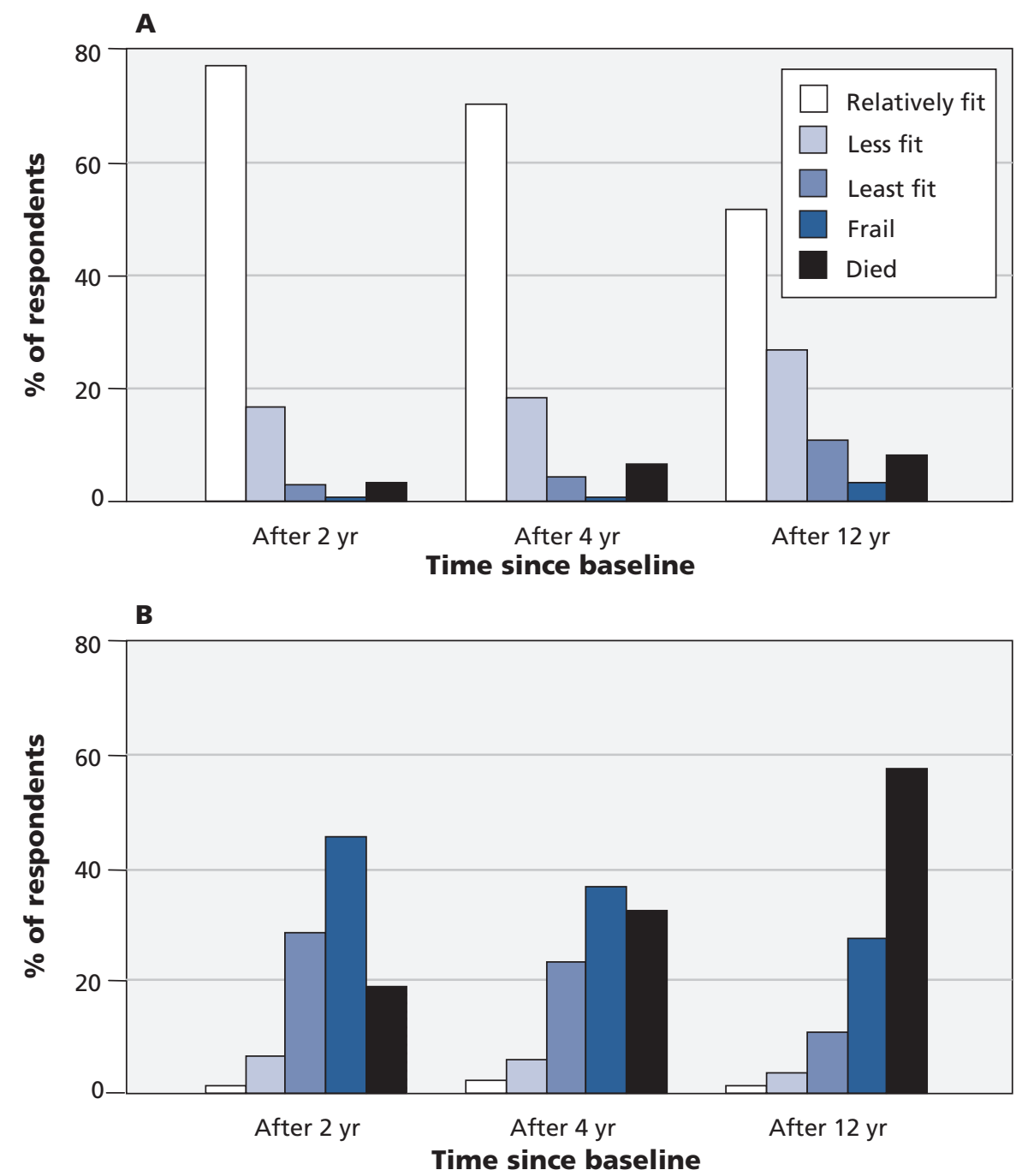

Figure 2: Transition of health state and mortality over 2, 4 and 12 years in people who were relatively fit (A, $n=7183)$ or frail $(B, n=1019)$ at baseline. Data are population-weighted. 
while the chance of becoming frail increased (Appendix 4, available at www.cmaj.ca/cgi/content /full/cmaj.101271/DC1). The proportion of people who were relatively fit at both cycle 1 and cycle 7 but whose health status had fluctuated in between also declined with age, especially after about midadulthood, as recovery to the fittest state became less likely. The lines mapping decline from the relatively fittest state (to any state) and decline to the frail state (from any state) crossed at about age 65 years. Those who declined sooner were more likely to be women (female/male ratio 1.2:1) and more likely to report a hospital stay in the two weeks preceding the survey ( $9 \%$ v. $4 \% ; p<0.01)$.

Frailty was associated with use of health care services. The risk of admission to a long-term care institution rose as baseline Frailty Index increased: $0.7 \%$ (95\% CI $0.4 \%-0.9 \%$ ) for the relatively fittest respondents, $1.8 \%$ (95\% CI $1.4 \%-2.2 \%)$ for the less fit, $4.5 \%$ (95\% CI $3.5 \%-5.4 \%$ ) for the least fit and $12.5 \%$ (95\% CI $10.2 \%-14.9 \%)$ for the frail respondents. The median time to admission to an institution was 61.2 months for the relatively fittest people and 34.2 months for those who were frail (log-rank test; $p<0.001)$. Other states were associated with intermediate intervals to admission to an institution (data not shown). Similarly, frailty was associated with a higher chance of having been in hospital in the two weeks preceding the survey, both at baseline (5.0\% [95\% CI 4.2\%$5.3 \%$ ] for the relatively fittest participants v. $18.4 \%$ [ $95 \%$ CI $16.4 \%-20.5 \%$ ] for the frail participants) and at follow-up. Relative to all other groups, a greater proportion of people who were

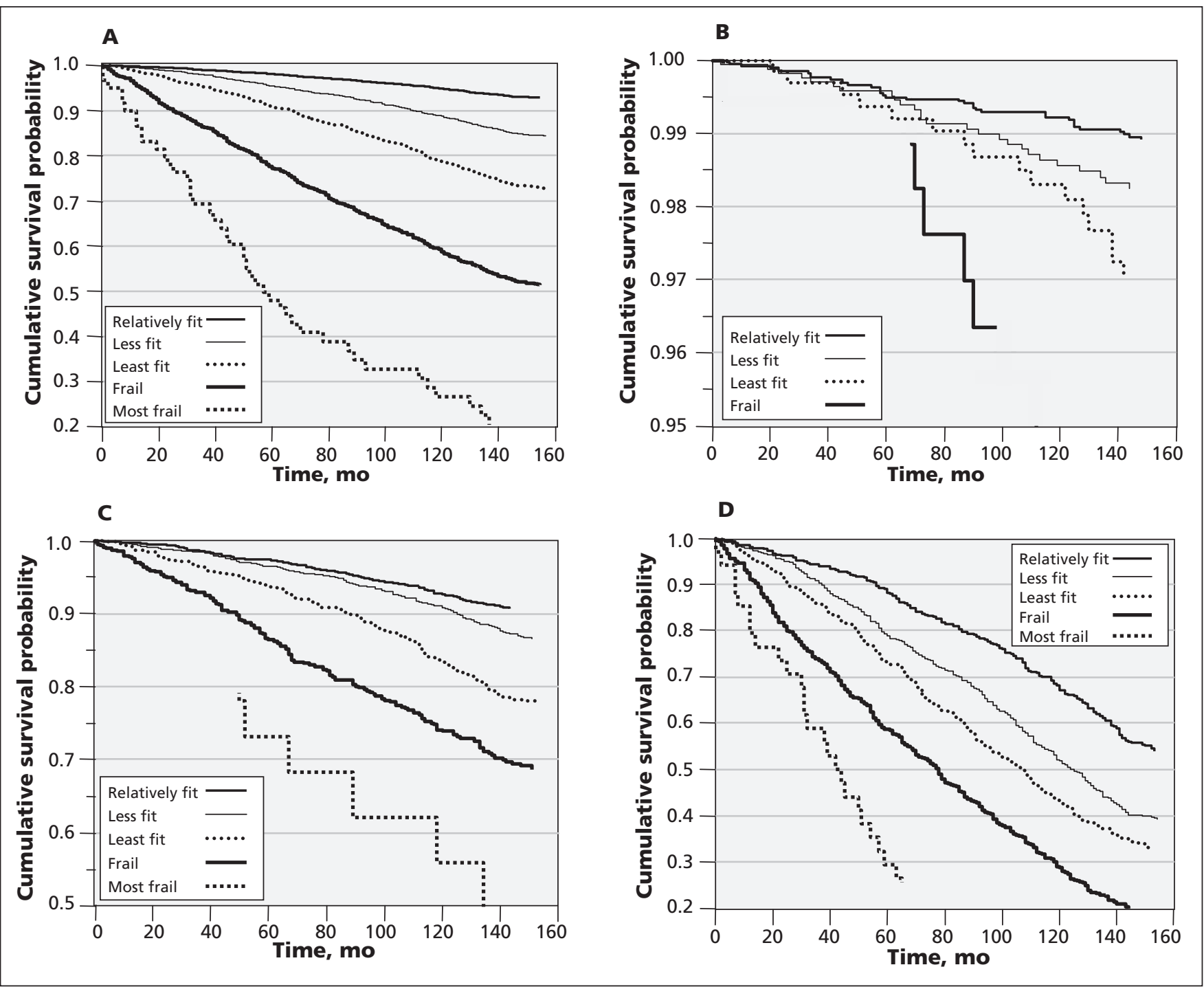

Figure 3: Kaplan-Meier probability of survival over 12 years, according to baseline health status, for all respondents at least 15 years of age (A) and for three age groups: 15-39 years (B), 40-69 years (C) and 70 years or older (D). The numbers of respondents for various levels of mortality risk over time are presented in Table 2. In keeping with Statistics Canada's privacy policy, data are not shown where samples sizes were less than six (e.g., for the "most frail" category in Figure 3B and for some points in the "most frail" category in Figure 3C). 
classified as most frail used health services at baseline $(28.3 \%, 95 \%$ CI $21.5 \%-35.5 \%)$ and at each follow-up (26.7\%, 95\% CI 15.4\%-28.0\%). Use of health services was also age-dependent. Among survivors who were frail at baseline, $10.3 \%$ (95\% CI 5.9\%-14.6\%) of middle-aged or younger people (age 15-69 years) had a hospital stay in the two weeks preceding the final survey. This proportion increased to $29.9 \%$ (95\% CI $21.1 \%-38.7 \%$ ) among older frail people (aged 70 or older).

The degree of frailty was closely related to survival at all ages (Figure 3, Table 2). At all values of the Frailty Index, mortality increased exponentially with age. At all ages, the 160month mortality rate was lower among relatively fit people than among those who were frail (e.g., $2 \%$ v. $16 \%$ at age $40 ; 42 \%$ v. $83 \%$ at age 75 or older). Similarly, mortality increased by age

Table 2: Number of people at risk and deaths over time, by age group*

\begin{tabular}{|c|c|c|c|c|}
\hline \multirow[b]{2}{*}{$\begin{array}{l}\text { Age group; } \\
\text { date of follow-up }\end{array}$} & \multicolumn{4}{|c|}{ Fitness category; no. of deaths } \\
\hline & $\begin{array}{l}\text { Relatively } \\
\text { fit }\end{array}$ & Less fit & Least fit & Frailt \\
\hline \multicolumn{5}{|l|}{ Age $\geq 15$ yr } \\
\hline No. at risk & 7183 & 3887 & 2038 & 1019 \\
\hline \multicolumn{5}{|l|}{ Deaths } \\
\hline By 4-yr follow-up & 120 & 146 & 145 & $\geq 201$ \\
\hline By 8-yr follow-up & 274 & 331 & 341 & $\geq 358$ \\
\hline By 12-yr follow-up & 453 & 581 & 508 & 478 \\
\hline \multicolumn{5}{|l|}{ Age 15-39 yr } \\
\hline No. at risk & 4048 & 1701 & 671 & 161 \\
\hline \multicolumn{5}{|l|}{ Deaths } \\
\hline By 4-yr follow-up & 15 & 10 & 6 & - \\
\hline By 8-yr follow-up & 32 & 18 & 12 & - \\
\hline By 12-yr follow-up & 43 & 28 & 19 & 9 \\
\hline \multicolumn{5}{|l|}{ Age 40-69 yr } \\
\hline No. at risk & 2728 & 1641 & 917 & 457 \\
\hline \multicolumn{5}{|l|}{ Deaths } \\
\hline By 4-yr follow-up & 66 & 51 & 49 & 52 \\
\hline By 8-yr follow-up & 144 & 115 & 125 & 101 \\
\hline By 12-yr follow-up & 226 & 215 & 203 & 142 \\
\hline \multicolumn{5}{|l|}{ Age $\geq 70 \mathrm{yr}$} \\
\hline No. at risk & 407 & 545 & 450 & 401 \\
\hline \multicolumn{5}{|l|}{ Deaths } \\
\hline By 4-yr follow-up & 39 & 85 & 90 & 146 \\
\hline By 8-yr follow-up & 98 & 198 & 204 & 252 \\
\hline By 12-yr follow-up & 176 & 328 & 305 & 326 \\
\hline \multicolumn{5}{|c|}{$\begin{array}{l}\text { *The population-weighted data in this table correspond to data presented in Figure } 3 \text {. In } \\
\text { keeping with the privacy policy of Statistics Canada, no data are shown for the } 1 \% \text { of } \\
\text { participants categorized as "most frail," as some points would have had values less than six. } \\
\text { tDash represents sample size less than six, which cannot be displayed because of the privacy } \\
\text { policy of Statistics Canada. }\end{array}$} \\
\hline
\end{tabular}

group. Even so, within each age group, separation between the survival curves by the level of frailty was evident (Figure 3B-3D). For the youngest group, differences in survival curves were statistically significant only between those with the lowest and the highest Frailty Index scores (Figure 3B; log-rank $p<0.001$ ) and between those with the lowest and the secondhighest Frailty Index scores (log-rank $p=0.015)$. Furthermore, separation of the survival curves for younger people was significant only after five to six years.

Both age and the Frailty Index significantly predicted mortality, adjusted by age, sex and level of education (Table 3), although the risk of death was associated more with deficits than with age, especially in young adulthood. Women consistently had a lower mortality risk at any age (Table 3) and at any level of frailty (data not shown). Higher level of education was associated with moderately reduced risk (by 6\%, 95\% CI 3\%-7\%, for the middle age group [40-69 years old] and by $4 \%, 95 \%$ CI $1 \%-6 \%$, for the older age group [70 years or older]; Table 3 ).

\section{Discussion}

In a Canadian population-based, medium-term cohort study based on a readily operationalized summary measure, we found that the prevalence of frailty increased exponentially with age throughout the adult lifespan, not just after age 65, where the sharpest inflection of the curve occurred. At all ages, relatively fit people had a lower risk of death and used fewer health care services. Younger people were most likely to maintain the highest levels of relative fitness or to recover to these levels if they became less well at the time of an interval survey. At all ages, a higher value of the Frailty Index was associated with higher mortality and greater use of health care services. Interestingly, although absolute mortality in relation to frailty was higher with increasing age, the relative risk of mortality in relation to frailty was highest for younger people.

That deficits accumulate with age is not surprising. Indeed, at the subcellular level, this is said to be how aging occurs. ${ }^{25}$ Our data suggest that the accumulation of deficits is a fact of aging, not age, and that the antecedents of frailty in late life manifest at least by middle age. We observed exactly the same exponential increase for all seven cycles of the survey (Figure 1A), which strikingly corresponded with age-mortality curves. As a first approximation, it appears that mortality is closely related to age because age is so closely related to the accumulation of deficits.

Prognosticating the risk of adverse outcomes 
on the basis of accumulation of deficits, and not just age, has useful clinical potential, but it requires a means of quantifying deficits. Here, counting deficits in a Frailty Index helped to define the risk of adverse outcomes for people of the same chronological age. This method appears to be robust, since inferences do not depend on whether the data use self-reported, clinical or performance-based frailty indices. ${ }^{2}$ In addition, the slope of the line relating the logarithmic mean of the Frailty Index to age was 0.029 (95\% CI 0.027-0.031), exactly at the median estimate for all prior data. ${ }^{2}$ The $99 \%$ limit at 0.67 is similarly consistent with prior data. ${ }^{21}$

The people who were relatively fittest at baseline were most likely to stay healthy, although the chance of doing so declined with age. We saw constant fluctuation in fitness status, with about $25 \%$ of people moving in and out of the relatively fit category over the course of the study (Appendix 4, available at www.cmaj.ca /cgi/content/full/cmaj.101271/DC1). Even so, although the fitness status of those who started in poor health could improve, these people were unlikely to attain the highest fitness levels as they aged. Otherwise, fluctuation in health status is not easily summarized, a point recently made with regard to older adults ${ }^{26}$ and which was the case here for younger people as well. Understanding fluctuation will probably benefit from dynamic systems modelling, rather than analyses of risk factors for decline.

\section{Limitations}

These data must be interpreted with caution. Fitness was defined on the basis of self-reported data, such that the relatively fittest people were those who reported having the least things wrong with them. Grades of fitness can be recognized even among such people. For example, higher aerobic fitness would be likely among people whose work requires aerobic conditioning or those who pursue such training recrea tionally. Similarly, people who report having many deficits might be able to mitigate their frailty through exercise. ${ }^{27}$ Even so, the clear relation between the Frailty Index and adverse outcomes suggests that this approach offers a good guide and is feasible for use in population studies. Whether it can also be used clinically is the subject of ongoing inquiry, although it is already known that deficit counts based on clinical data are related to short-term outcomes in clinical settings. ${ }^{28,29}$

For nearly one person in four, data were missing for at least one of the seven cycles. Overall, nonrespondents had slightly (but not statistically) higher values of the Frailty Index. Given that nonresponse likely leads to underestimation of the adverse outcomes of deficit accumulation, our estimates are conservative. In addition, we did not consider the social context in which frail people find themselves, even though the ways in which health and social deficits interact further defines the degree of risk. ${ }^{30}$

\section{Conclusion}

These data show that the accumulation of deficits is closely linked to mortality and to admission to hospital or to an institution. For this reason, providers of various health care services, especially hospitals, may wish to re-evaluate the normative status given to the "one diagnosis at a time" approach, which remains the mainstay of medical teaching, textbooks and the organization of clinical services. Our data suggest that it is not coincidence that use of hospital services increases in step with accumulation of deficits. Frailty, in all its complexity, challenges how we care for people. A particular challenge is to determine how insights about the complexity of frailty can be translated into a new approach to

Table 3: Hazard ratios for 12-year survival, based on multivariable Cox regression models for different age groups

\begin{tabular}{|lcccc|}
\hline & \multicolumn{4}{c|}{ Characteristic; hazard ratio* (95\% Cl) } \\
\cline { 2 - 5 } Age group, yr & Frailty Index & Age & Sex & Education \\
\hline All & $1.04(1.03-1.04)$ & $1.08(1.08-1.09)$ & $0.54(0.50-0.59)$ & $0.96(0.94-0.97)$ \\
\hline $15-39$ (younger) & $1.06(1.03-1.08)$ & $1.07(1.04-1.11)$ & $0.41(0.26-0.65)$ & $0.95(0.89-1.03)$ \\
\hline $40-69$ (middle) & $1.04(1.03-1.05)$ & $1.08(1.07-1.09)$ & $0.53(0.46-0.61)$ & $0.94(0.93-0.97)$ \\
\hline$\geq 70$ (older) & $1.03(1.03-1.04)$ & $1.08(1.07-1.10)$ & $0.56(0.50-0.63)$ & $0.96(0.94-0.99)$ \\
\hline $\begin{array}{l}\text { Note: Cl = confidence interval. } \\
\text { *Hazard ratios represent the risk of death associated with 1\% increments in the Frailty Index, one-year increments of age and } \\
\text { education, and being female. The reference values of the covariates are 0 for Frailty Index, minimal age (in each age group), } \\
\text { minimal level of education and being male, respectively. For example, in the middle-aged group, a 50-year-old person with } \\
\text { Frailty Index of 0.2 (i.e., 20\%) would have an age-associated relative risk of death of 2.16 (i.e., exp[In(1.08) } \times \text { (50-40)]) and a } \\
\text { Frailty Index-associated relative risk of death of 2.19 (i.e., exp[In(1.04) } \times 20]) .\end{array}$ \\
\hline
\end{tabular}


assessing and quantifying disease for patients who are frail, especially when they become acutely ill.

\section{References}

1. Abellan van Kan G, Rolland Y, Houles M, et al. The assessment of frailty in older adults. Clin Geriatr Med 2010;26:275-86.

2. Rockwood K, Mitnitski A. Frailty defined by deficit accumulation and geriatric medicine defined by frailty. Clin Geriatr Med 2011;27:17-26.

3. Rockwood K, Andrew M, Mitnitski A. A comparison of two approaches to measuring frailty in elderly people. J Gerontol A Biol Sci Med Sci 2007;62:738-43.

4. Kulminski AM, Ukraintseva SV, Kulminskaya IV, et al. Cumulative deficits better characterize susceptibility to death in elderly people than phenotypic frailty: lessons from the Cardiovascular Health Study. J Am Geriatr Soc 2008;56:898-903.

5. Kulminski A, Yashin A, Ukraintseva S, et al. Accumulation of health disorders as a systemic measure of aging: findings from the NLTCS data. Mech Ageing Dev 2006;127:840-8.

6. Strawbridge WJ, Shema SJ, Balfour JL, et al. Antecedents of frailty over three decades in an older cohort. J Gerontol B Psychol Sci Soc Sci 1998;53:S9-16.

7. Barzilay JI, Blaum C, Moore T, et al. Insulin resistance and inflammation as precursors of frailty: the Cardiovascular Health Study. Arch Intern Med 2007;167:635-41.

8. Kuh D, Hardy R, Butterworth S, et al. Developmental origins of midlife grip strength: findings from a birth cohort study. J Geronto A Biol Sci Med Sci 2006;61:702-6.

9. Mitnitski A, Song X, Rockwood K. Improvement and decline in health status from late middle age: modeling age-related changes in deficit accumulation. Exp Gerontol 2007;42:1109-15.

10. Gill TM, Gahbauer EA, Allore HG, et al. Transitions between frailty states among community-living older persons. Arch Intern Med 2006; 166:418-23.

11. National Population Health Survey household component cycle 1 to 7 (1994/1995 to 2006/2007) longitudinal documentation. Ottawa (ON): Statistics Canada; 2008. Available: www.statcan .gc.ca/imdb-bmdi/document/3225_D5_T1_V4-eng.pdf (accessed 2009 Feb. 20).

12. Singh MP, Tambay JL, Krawchuk S. The National Population Health Survey: design and issues. In: Proceedings of the Survey Research Methods Section, American Statistical Association; 1994. p. 803-8. Available: www.amstat.org/sections/srms/proceedings /papers/1994 138.pdf (accessed 2009 Feb. 20).

13. Dupre ME, Gu D, Warner DF, et al. Frailty and type of death among older adults in China: prospective cohort study. BMJ 2009;338:b1175.

14. Goggins WB, Woo J, Sham A, et al. Frailty index as a measure of biological age in a Chinese population. J Gerontol A Biol Sci Med Sci 2005;60:1046-51

15. Ridda I, Macintyre CR, Lindley R, et al. Immunological responses to pneumococcal vaccine in frail older people. Vaccine 2009;27:1628-36

16. Hubbard RE, O'Mahony MS, Woodhouse KW. Characterising frailty in the clinical setting - a comparison of different approaches. Age Ageing 2009;38:115-9.

17. García-González JJ, García-Peña C, Franco-Marina F, et al. A frailty index to predict the mortality risk in a population of senior Mexican adults. BMC Geriatr 2009;9:47.

18. Hastings SN, Purser JL, Johnson KS, et al. Frailty predicts some but not all adverse outcomes in older adults discharged from the emergency department. J Am Geriatr Soc 2008;56: 1651-7.
19. Yang Y, Lee LC. Dynamics and heterogeneity in the process of human frailty and aging: evidence from the U.S. older adult population. J Gerontol B Psychol Sci Soc Sci 2010;65B:246-55.

20. Song X, Mitnitski A, Rockwood K. Prevalence and 10-year outcomes of frailty in older adults in relation to deficit accumulation. J Am Geriatr Soc 2010;58:681-7.

21. Rockwood K, Mitnitski A. Limits to deficit accumulation in elderly people. Mech Ageing Dev 2006;127:494-6.

22. Rockwood K, Song X, MacKnight C, et al. A global clinical measure of fitness and frailty in elderly people. CMAJ 2005; 173:489-95.

23. Fried LP, Tangen CM, Walston J, et al. Frailty in older adults: evidence for a phenotype. J Gerontol A Biol Sci Med Sci 2001; 56:M146-56.

24. Allison PD. Missing data. Thousand Oaks (CA): Sage; 2002

25. Kirkwood TB. Understanding the odd science of aging. Cell 2005;120:437-47.

26. Gill TM, Gahbauer EA, Han L, et al. Trajectories of disability in the last year of life. N Engl J Med 2010;362:1173-80.

27. Hubbard RE, Fallah N, Searle SD, et al. Impact of exercise in community-dwelling older adults. PLoS One 2009;4:e6174.

28. Ensrud KE, Ewing SK, Taylor BC, et al. Comparison of 2 frailty indexes for prediction of falls, disability, fractures, and death in older women. Arch Intern Med 2008;168:382-9.

29. Rockwood K, Rockwood MR, Andrew MK, et al. Reliability of the hierarchical assessment of balance and mobility in frail older adults. J Am Geriatr Soc 2008;56:1213-7.

30. Andrew MK, Mitnitski AB, Rockwood K. Social vulnerability, frailty and mortality in elderly people. PLoS One 2008;3:e2232.

Affiliations: From the Division of Geriatric Medicine (Rockwood, Song, Mitnitski), Department of Medicine, Dalhousie University, Halifax, NS; the Centre for Health Care of the Elderly (Rockwood), Queen Elizabeth II Health Sciences Centre, Capital District Health Authority, Halifax, NS; the Institute for Biodiagnostics — Atlantic (Song), National Research Council, Halifax, NS; and the Department of Mathematics and Statistics (Mitnitski), Dalhousie University, Halifax, NS

Contributors: Kenneth Rockwood conceived of the study and wrote the first draft of the manuscript. Xiaowei Song and Arnold Mitnitski performed the analyses. All authors contributed to revising the paper and approved the final version submitted for publication. The authors had full access to all of the data presented in the paper and take responsibility for the integrity of the data and the accuracy of the data analysis.

Funding: This project was sponsored by an operating grant from the Canadian Institutes of Health Research, no. MOP64169. Kenneth Rockwood receives career support from the Dalhousie Medical Research Foundation as the Kathryn Allen Weldon Professor of Alzheimer Research.

Acknowledgements: The National Population Health Study was carried out by Statistics Canada. The authors obtained access to the data through an agreement with the Atlantic Research Data Centre of Statistics Canada, which obliged them to operate, for these purposes only, as "deemed employees" of Statistics Canada. Statistics Canada officials reviewed the analyses to ensure that confidentiality had not been breached and that the data were weighted properly to produce uniform estimates across reports. In no other way did any sponsor have influence over the data analyses. 